\title{
The separation of softwood and hardwood in historical wooden statues of the Nazenji-temple in Japan using NIR spectroscopy
}

\author{
Hisashi Abe $^{1, *}$, Yohei Kurata ${ }^{2}$, Ken Watanabe ${ }^{1}$, Atsuko Ishikawa ${ }^{1}$, Shuichi Noshiro3, \\ Tomoyuki Fujii' ${ }^{1}$, Mitsuharu Iwasa ${ }^{4}$, Hiroaki Kaneko ${ }^{5}$, and Hiroshi Wada ${ }^{5}$ \\ ${ }^{1}$ Forestry and Forest Products Research Institute, Tsukuba, Ibaraki, Japan \\ ${ }^{2}$ Nihon University, Fujisawa, Kanagawa, Japan \\ ${ }^{3}$ Meiji University, Kanda Sarugakucho, Chiyoda-ward, Tokyo, Japan \\ ${ }^{4}$ Seijo University, Setagaya-ward, Tokyo, Japan \\ 5Tokyo National Museum, Ueno Park, Taito-ward, Tokyo, Japan \\ ${ }^{*}$ Corresponding author; email: abeq@affrc.go.jp \\ Accepted for publication: 18 August 2020
}

\begin{abstract}
The applicability of near-infrared (NIR) spectroscopy to the identification of wood species of archaeologically/historically valuable wooden artifacts in a non-invasive manner was investigated using reference wood samples from the xylarium of the Forestry and Forest Products Research Institute (TWTw) and applied to several wooden statues carved about 1000 years ago. Diffuse-reflectance NIR spectra were obtained from five standard wood samples each of five softwood species (Chamaecyparis obtusa, Cryptomeria japonica, Sciadopitys verticillata, Thujopsis dolabrata, Torreya nucifera) and five hardwood species (Aesculus turbinata, Cercidiphyllum japonicum, Cinnamomum camphora, Prunus jamasakura, Zelkova serrata). A principal component analysis (PCA) model was developed from the second derivative spectra. The score plot of the first two components clearly showed separation of the wood sample data into softwood and hardwood clusters. The developed PCA model was applied to 370 spectra collected from 21 wooden statues preserved in the Nazenji-temple in Shizuoka Prefecture in Japan, including 14 made from Torreya spp. and 7 made from Cinnamomum spp. In the score plot, the statue spectra were also divided into two clusters, corresponding to either softwood (Torreya spp.) or hardwood (Cinnnamomum spp.) species. These results show that NIR spectroscopy combined with PCA is a powerful technique for determining whether archaeologically/historically valuable wooden artifacts are made of softwood or hardwood.
\end{abstract}

Keywords: near infrared spectroscopy; wooden statue; wood species; softwood; hardwood. 


\section{INTRODUCTION}

The identification of wood species in objects of archaeological/historical significance is important both for repairing and maintaining the artifacts themselves as well as for gaining an understanding of their historical and cultural backgrounds. The most common approach to identifying wood species in such cases is to examine samples obtained from the artifacts. In Japan, however, taking samples from designated cultural properties is avoided to minimize damage.

For over 20 years, we have been determining wood species of wooden statues by collecting minute, naturally detached fragments and observing them with mostly optical and partly scanning-electron microscopy (Kaneko et al. 1998, 2003, 2010). These studies have shown that in Japan only a limited number of species were used for carving ancient wooden statues. One problem with this approach, however, is that it is sometimes difficult to obtain samples that are sufficient in both quality and quantity for making a definitive identification. For this reason, it is important to develop alternative methods in which artifacts can be examined non-invasively.

In recent years, near-infrared (NIR) spectroscopy has emerged as a relatively popular method of wood species identification because of its availability and conventionality. Brunner et al. (1996) and Schimleck et al. (1996) both used principal component analysis (PCA) and subsequent score plots to illustrate NIR's potential for differentiating wood species. Since then, NIR in combination with chemometric analysis has been used to successfully identify wood species or wood-based materials (Furumoto et al. 1999; Tsuchikawa et al. 2003a-c; Gierlinger et al. 2004; Flæte et al. 2006; Adedipe et al. 2008; Watanabe et al. 2011; Abe et al. 2015, 2016; Horikawa et al. 2015). In most studies, however, the origin of the wood samples was not considered, and studies using internationally recognized wood samples kept in xylaria were limited (Watanabe et al. 2011; Abe et al. 2015, 2016; Horikawa et al. 2015). Using wood samples stored in a xylarium, it was found that, with NIR spectroscopy using 830-250o nm of wavelength and PCA, it was possible to distinguish between softwood and hardwood that had been stored for over 50 years (Abe et al. 2015).

Various conditions of light intensity, temperature, and humidity to which most wooden artifacts (or those containing wood) have been exposed for long periods of time, inevitably lead to variability in the wood properties of these artifacts, which may create difficulties when trying to identify wood species using NIR. Thus, to evaluate the effectiveness of NIR spectroscopy for the non-invasive identification of wood species in archaeological/historical artifacts, we first analyzed the results of our previous study (Abe et al. 2015), in which we utilized wood samples from the xylarium at the Forestry and Forest Products Research Institute (TWTw) as references. We then applied the results obtained to the examination of wooden statues that have been preserved at a Buddhist temple for about 1000 years. In this study, we focused on the possibility of differentiating between softwood and hardwood species. 
Table 1.

Samples used for the experiment.

\begin{tabular}{lll}
\hline Scientific name & Common name & Sample number (TWTw) \\
\hline Chamaecyparis obtusa & Hinoki & $15,873,14668,21542,26263$ \\
Cryptomeriajaponica & Sugi & $96,6427,9290,10275,14914$ \\
Sciadopitys verticillata & Koyamaki & $648,850,9473,18330,24262$ \\
Thujopsis dolabrata & Asunaro & $864,876,20342,24322,25023$ \\
Torreya nucifera & Kaya & $852,4332,9272,13662,14504$ \\
Aesculus turbinata & Tochi & $6389,9476,13912,18349,26346$ \\
Cercidiphyllum japonicum & Katsura & $81,1306,4339,7989,13665$ \\
Cinnamomum camphora & Kusu & $27,770,933 \circ, 20323,21271$ \\
Prunus jamasakura & Sakura & $846,6325,9333,24605,25378$ \\
Zelkova serrata & Keyaki & $6425,9326,13676,18339,19836$ \\
\hline
\end{tabular}

\section{MATERIALS AND METHODS}

\section{Classification analysis by using principal component analysis with modern wood}

For the separation of wood samples into softwood and hardwood, we used the PCA model which we established in our previous paper (Abe et al. 2015).

We selected 5 softwood species (Chamaecyparis obtusa, Cryptomeria japonica, Sciadopitys verticillata, Thujopsis dolabrata, Torreya nucifera) and 5 hardwood species (Aesculus turbinata, Cercidiphyllum japonicum, Cinnamomum camphora, Prunus jamasakura, Zelkova serrata) known to be used in ancient wooden statues as reference materials. Five wood samples of each species collected from various sites in Japan and stored in the xylarium of the Forestry and Forest Products Research Institute (TWTw) were used for the analysis (Table 1). Wood samples containing both sapwood and heartwood in one piece were selected for the measurements. The specimens were stored in the collection room, which is conditioned at a temperature range of $20-30^{\circ} \mathrm{C}$ and a relative humidity of about $50-80 \%$. Prior to NIR measurement, the tangential and radial faces were sanded with 180 -mesh sand paper.

For NIR measurement, the diffuse reflectance spectra of a spot ( $3 \mathrm{~mm}$ diameter) were collected at $4 \mathrm{~cm}^{-1}$ intervals over a range of $12000-4000 \mathrm{~cm}^{-1}(830-2500 \mathrm{~nm})$ using a MATRIX-F spectrometer (Bruker Optics) equipped with an NIR fiber optic probe. A piece of commercial resin, Spectralon, was used as a reference material. Five spectra each were randomly collected from the heartwood and sapwood of tangential and radial surfaces. When samples did not include both sapwood and heartwood, five spectra were obtained from either sapwood or heartwood. All the spectra were acquired at $20 \pm 2{ }^{\circ} \mathrm{C}$ and $65 \pm 5 \%$ relative humidity.

For the development of the PCA model, the spectra were pre-processed with SavitzkyGolay second derivations with 21 convolution points. PCA was performed using the Unscrambler X software, version 10.2 (CAMO, Montclair, NJ, USA). All the NIR spectra, obtained from both the radial and tangential surfaces of sapwood and heartwood, were used 
together for PCA, because it was difficult to differentiate sapwood vs. heartwood and tangential vs. radial surface from the wood of the old artifacts.

Separating wood into softwood or hardwood was performed by the soft independent modeling of class analogy (SIMCA) method (Dunn \& Wold 1980; Tominaga 1999; MezaMarquez et al. 2010). SIMCA is a supervised classification method. A PCA is performed for each of the categories in the training data set. The PCA models developed are then employed to compute a measure of the distance of the unknown samples to the model center, which in the Unscrambler software is called leverage. Whether the unknown samples belong to a category or not is determined based on these leverage values. In this study, SIMCA was based on the softwood and hardwood PCA models. The final numbers of the principal components (PCs) were recommended by the Unscrambler software, and the PC numbers for the softwood model and the hardwood model were 6 and 4, respectively. The leverage was used as the criteria to determine whether the softwood or hardwood sample belongs to either one category (softwood or hardwood), to several classes (both softwood and hardwood), or to no class (neither softwood nor hardwood).

\section{Spectra acquisition from ancient artifacts and analysis}

A total of 370 spectra were collected on site from the surfaces of 21 wooden statues kept at the Nazenji-temple in Kawazu-cho, Shizuoka Prefecture in Japan (http://kawazuheian. sakura.ne.jp/index.html). The statues from which we obtained spectra were most likely created in the mid-Heian period (9-11th century), and each statue was carved from a single piece of timber. Spectra were obtained from surfaces from which the paint and lacquer had been removed. The surfaces where the spectra were obtained included radial, tangential, and transitional surfaces between radial and tangential surfaces.

Naturally detached wood fragments collected from the statues were identified with light microscopy as Torreya spp. for 14 and Cinnamomum spp. for 7 statues, respectively (Table 2). The wood of other species was not used to make the statues at that temple.

The 370 spectra of these ancient statues were projected into the score plots of the PCA model. The separation of ancient wood into softwood and hardwood was carried out using the SIMCA model. In this study, the percentage of classification result obtained from each spectrum of 21 wooden statues was summarized.

\section{RESULTS AND DISCUSSION}

Using the PCA model developed from reference samples, spectra from wooden statues were projected onto the score plots of the model (Fig. 1). Most of the plots fell within the softwood and hardwood clusters of reference samples, and the separation of softwood and hardwood was still recognizable in the score plots of the wooden statues. This suggests that the developed PCA model is quite effective for the separation of ancient wooden artifacts into softwood and hardwood. Although the PCA model was developed using the NIR spectra collected from a limited number of reference samples, attention paid to the variety of samples, such as wood species, collection site, radial/tangential surfaces and sapwood/heartwood seemed important to obtain an effective PCA model. This measuring procedure is believed to be very useful when a robust NIR calibration is established. 
Table 2.

Types and genus of the investigated statues.

\begin{tabular}{rlll}
\hline No & Type of statue & Japanese name & Genus \\
\hline 1 & Deity & Tenbu & Torreya \\
2 & Eleven-headed Avalokitesvara & Jūichimen Kannon & Torreya \\
3 & Deity & Tenbu & Torreya \\
4 & Bodhisattva & Bosatsu & Torreya \\
5 & Eleven-headed Avalokitesvara & Jūichimen Kannon & Torreya \\
6 & Bhaisajyaguru & Yakushi Nyorai & Torreya \\
7 & Brahma & Bonten & Torreya \\
8 & Śakro Indra & Taishakuten & Torreya \\
9 & Deity & Tenbu & Torreya \\
10 & Bodhisattva & Bosatsu & Torreya \\
11 & Deity & Tenbu & Torreya \\
12 & Deity & Tenbu & Torraya \\
13 & Buddhist priest & Sogyō & Torreya \\
14 & Shinto goddes & Nyoshin & Cinnamomum \\
15 & Shinto goddes & Nyoshin & Cinnamomum \\
16 & Shinto goddes & Nyoshin & Cinnamomum \\
17 & Shinto god & Danshin & Cinnamomum \\
18 & Shinto god & Danshin & Cinnamomum \\
19 & Shinto god & Danshin & Cinnamomum \\
20 & Bodhisattva & Bosatsu & Cinnamomum \\
21 & Deity & Tenbu & Cinnamomum \\
\hline & & &
\end{tabular}

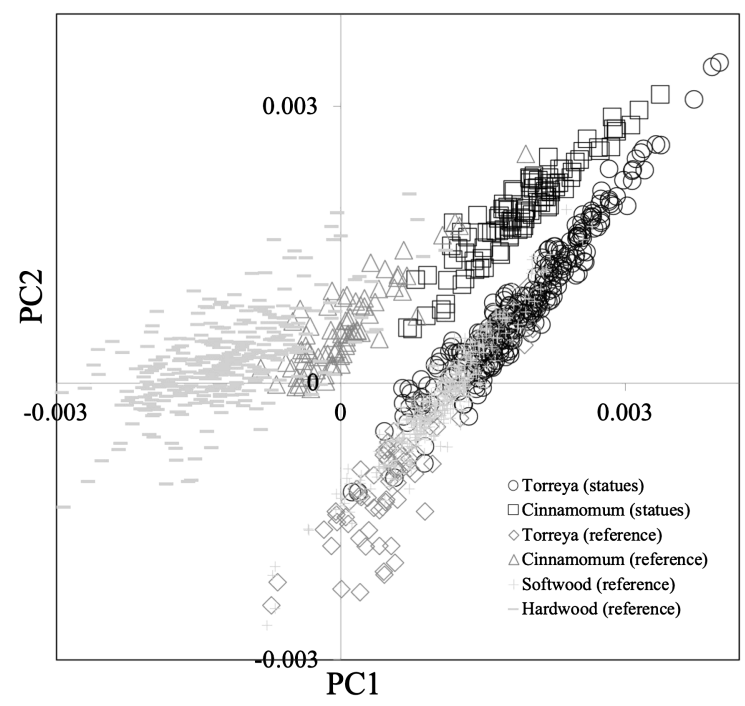

Figure 1. Score plots of the first and second principal components of spectra of wooden statues projected onto the PCA model for the separation between softwood and hardwood. 


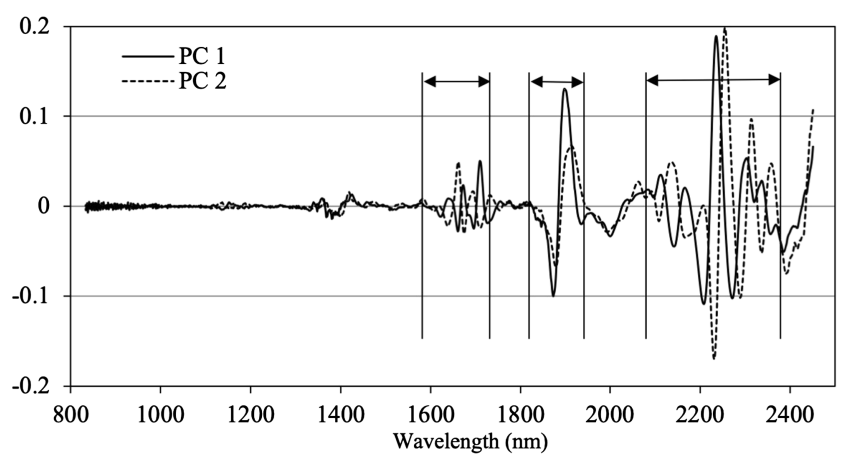

Figure 2. Loading spectra for principal components PC1 and PC2 (Modified form Abe et al. 2015).

The loading spectra of $\mathrm{PC} 1$ and $\mathrm{PC} 2$ showed that the PCA plots were strongly contributed by the ranges of $1600-175^{\circ} \mathrm{nm}, 185^{\circ}-1950 \mathrm{~nm}$ and 2100-2400 $\mathrm{nm}$ (Fig. 2). In these wavelength ranges, absorption caused by the first overtone of $-\mathrm{CH}$ vibrations, water, and the first overtone of $-\mathrm{OH}$, were reported to be recognized in the ranges of $1600-175 \mathrm{O} \mathrm{nm}$ and 1850-1950 nm, respectively, while various chemical bonds were recognized in the range of 2100-2400 nm (Ali et al. 2001; Bokobza 2002; Shenk et al. 2008; Fujimoto et al. 2010; Hein et al. 2011; Schwanninger et al. 2011). Because differences in the composition and structures of hemicellulose and lignin are well recognized between softwood and hardwood (Sjöström 1993), the vibrations of the chemical bonding from these chemical compositions are possibly the key to the separation of softwood and hardwood PCs.

The separation of the softwood and hardwood score plots remained recognizable in the score plots of the wooden statues, but the hardwood species cluster seemed to shift toward the softwood cluster (Fig. 1). Also, in the score plots of the old wooden statues, both softwood (Torreya) and hardwood (Cinnamomum) clusters shifted in a positive direction, as compared with the reference wood samples of Torreya and Cinnamomum, and came closer to each other. It appears that, over time, the chemical composition and chemical bonding of the wood of the hardwood artifacts changed, becoming more similar to the wood of the softwood artifacts.

Furthermore, when comparing the second derivatives of NIR spectra obtained from reference samples and from wooden statues of Torreya and Cinnamomum (Fig. 3), amplitude ranges of wooden statues were smaller than those of reference samples. Table 3 shows the classification results of SIMCA for softwood and hardwood with 21 wooden statues at the significance level of $0.05(\alpha=0.05)$. Spectra from the wooden statues of Torreya and Cinnamomum were classified with averaged accuracies of about $37 \%$ and $41 \%$ for most samples, respectively (Table 3). There was no case of classification into the wrong category. It was determined that $18 \%$ of the spectra from Torreya and $13 \%$ of the spectra from Cinnamomum were classified as "Several categories". The classification "Several categories" means that the spectra can potentially be categorized as both softwood and hardwood at the same time. This indicates that spectra obtained from wooden statues of both softwood and hardwood tend to have similar characteristics. It is suggested that chemical compositions of 


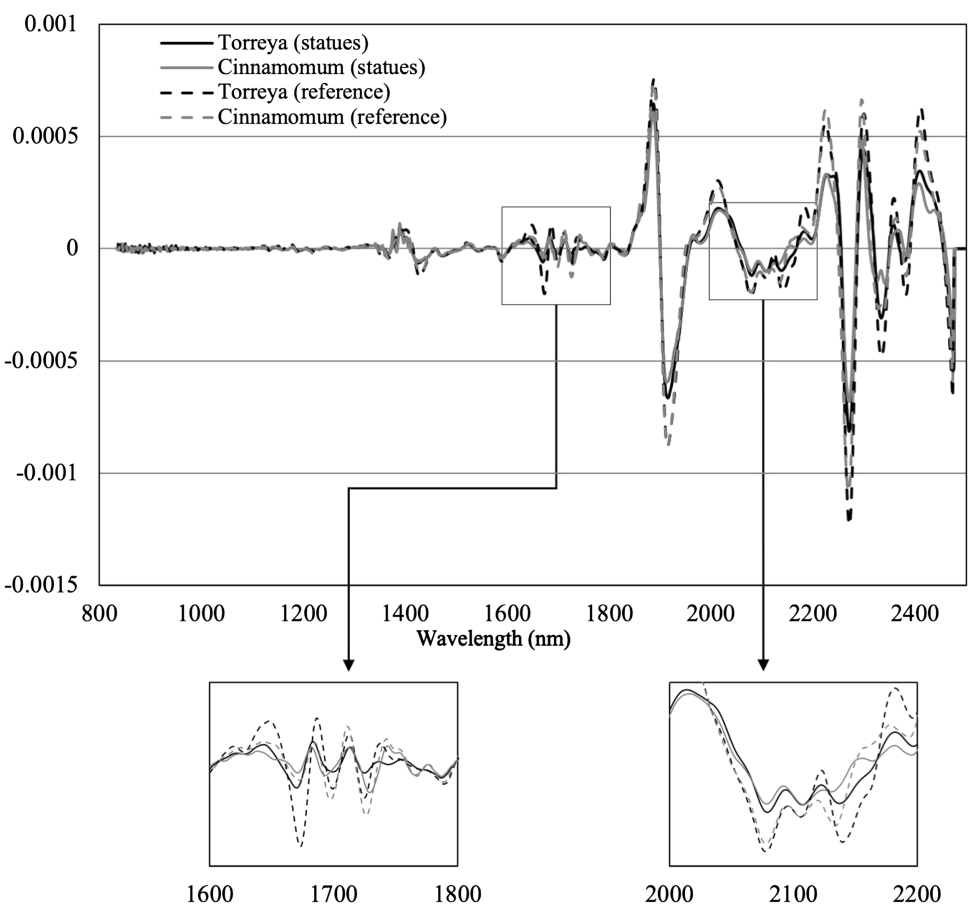

Figure 3. Comparison between average of second derivative of NIR spectra obtained from reference samples and from wooden statues of Torreya and Cinnamomum.

wooden statues become more similar with the degradation of wood composition over time. It has been reported that UV irradiation promotes lignin decomposition, and high humidity seems to accelerate degradation (Williams 2005). In this study, $45 \%$ of Torreya spectra and $46 \%$ of Cinnamomum spectra were classified as "No category". The classification "No category" means that the spectra don't contain enough information to make the separation between softwood or hardwood. It is speculated that the surfaces of the wooden statues affected the quality of the spectra, because they have been damaged by biodegradation, light, moisture, and so on. Statues in a more degraded condition tend to show lower ratios of correct classification (Fig. 4). From these results, it is suggested that for more accurate identification of wood species, we need to obtain spectra from the surface area with the least damage on each statue.

Because old wooden statues were variably influenced by light, temperature, humidity, and biological degradation over long periods of time, these factors influenced shifts in the score plot observed in the PCA. Tsuchikawa et al. (2004) monitored changes in the chemical composition of wood using NIR as samples degraded by UV irradiation, and reported decreases in the NIR absorbance bands assigned to cellulose (1432 nm), lignin (1672 nm) and hemicellulose $(1712 \mathrm{~nm})$. A continuing investigation of factors that influence the chemical composition of wood is necessary to improve the accuracy of NIR-facilitated separation of wood species in historically/archeologically important wooden artifacts. 
Table 3.

SIMCA classification of softwood and hardwood.

\begin{tabular}{|c|c|c|c|c|c|c|}
\hline No & Genus & $\begin{array}{l}\text { Number of } \\
\text { spectra }\end{array}$ & $\begin{array}{c}\text { Correct } \\
\text { classification }(\%)\end{array}$ & $\begin{array}{c}\text { Classified several } \\
\text { categories }(\%)\end{array}$ & $\begin{array}{c}\text { Classified wrong } \\
\text { category }(\%)\end{array}$ & $\begin{array}{l}\text { Classified no } \\
\text { category (\%) }\end{array}$ \\
\hline 1 & Torreya & 21 & 67 & 10 & o & 24 \\
\hline 2 & Torreya & 26 & 62 & 35 & o & 4 \\
\hline 3 & Torreya & 28 & 57 & 7 & o & 36 \\
\hline 4 & Torreya & 12 & 8 & 8 & o & 83 \\
\hline 5 & Torreya & 9 & 22 & o & o & 78 \\
\hline 6 & Torreya & 10 & $5^{\circ}$ & $\mathrm{O}$ & o & $5^{\circ}$ \\
\hline 7 & Torreya & 54 & 43 & 11 & o & 46 \\
\hline 8 & Torreya & 27 & 70 & 11 & o & 19 \\
\hline 9 & Torreya & 24 & 67 & 4 & o & 29 \\
\hline 10 & Torreya & 12 & o & o & o & 100 \\
\hline 11 & Torreya & 12 & 17 & 42 & o & 42 \\
\hline 12 & Torraya & 9 & 22 & 44 & o & 33 \\
\hline \multirow[t]{2}{*}{13} & Torreya & 24 & o & 63 & o & 38 \\
\hline & $\begin{array}{l}\text { Average of } \\
\text { Torreya }\end{array}$ & & 37 & 18 & o & 45 \\
\hline 14 & Cinnamomum & 12 & 33 & 17 & o & $5^{\circ}$ \\
\hline 15 & Cinnamomum & 18 & 33 & 56 & o & 11 \\
\hline 16 & Cinnamomum & 18 & 56 & 22 & o & 22 \\
\hline 17 & Cinnamomum & 6 & 17 & o & o & 83 \\
\hline 18 & Cinnamomum & 18 & 61 & o & o & 39 \\
\hline 19 & Cinnamomum & 15 & 47 & o & o & 53 \\
\hline 20 & Cinnamomum & 9 & 33 & 11 & o & $5^{6}$ \\
\hline \multirow[t]{2}{*}{21} & Cinnamomum & 6 & $5^{\circ}$ & o & o & $5^{\circ}$ \\
\hline & $\begin{array}{l}\text { Average of } \\
\text { Cinnamomum }\end{array}$ & & 41 & 13 & o & 46 \\
\hline
\end{tabular}

This study is the first investigation of wood species of archaeologically important wooden statues using NIR spectroscopy, and suggests the possibility of separating wood species in a non-invasive manner on site. We investigated 21 ancient wooden statues in this study, but plan to study an increased number of them at other temples. Our ultimate goal is to differentiate wood down to the species level in a non-invasive manner. Along with this, we plan to optimize the method of obtaining NIR spectra from artifacts and to choose informative wavelength ranges for analyses leading to the separation of wood species.

\section{CONCLUSIONS}

The applicability of NIR spectroscopy to the non-invasive identification of wood species found in archaeologically/historically valuable wooden artifacts was examined using wood reference samples from the collection of FFPRI and historical wooden statues preserved at a Buddhist temple for about 1000 years. PCA was performed with the second derivation of the NIR spectra. Using a PCA model obtained from reference samples, score plots of 

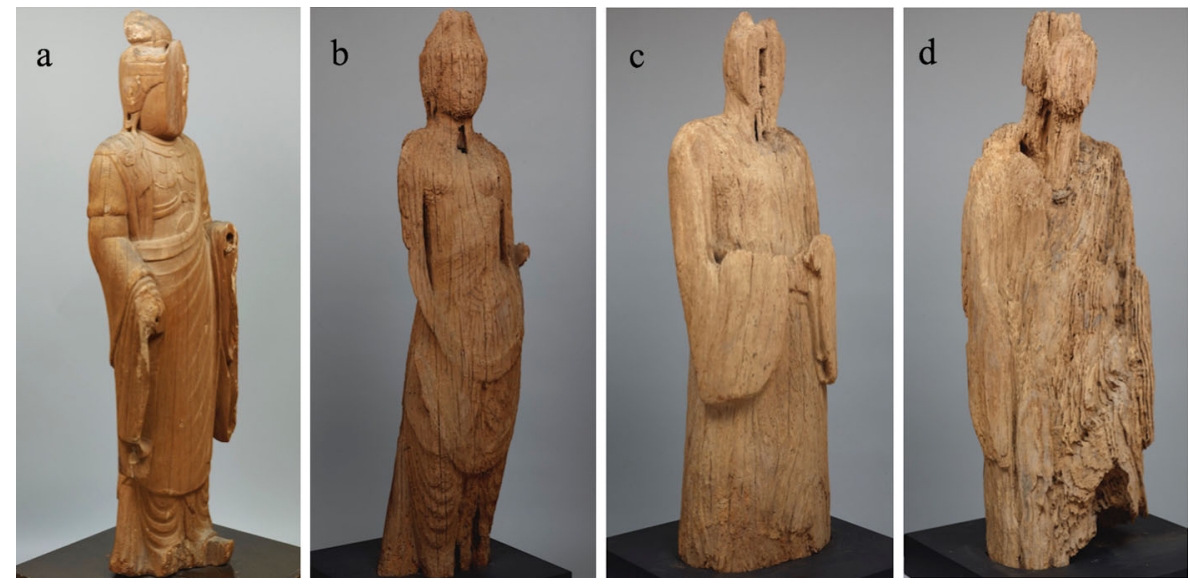

Figure 4. Wooden statues made of Torreya wood with the highest ratio of correct classification (of the statue no. 8) (a), and the lowest ratio of correct classification (of the statue no. 12) (b). Wooden statues made of Cinnamomum wood with the highest ratio of correct classification (of the statue no. 18) (c), and the lowest ratio of correct classification (of the statue no. 17) (d).

wooden artifacts clearly showed two clusters corresponding to softwood and the hardwood species. These results suggest that NIR spectroscopy combined with PCA is useful for separating wood species of archeological/historical wooden artifacts in a non-invasive manner with minimal sample preparation.

\section{ACKNOWLEDGEMENTS}

This research was supported by a Grant-in-Aid for Scientific Research (No 21300332, 25292109, 18Hoo631) from the Japan Society for the Promotion of Science (JSPS).

\section{REFERENCES}

Abe H, Watanabe K, Ishikawa A, Noshiro S, Fujii T, Iwasa M, Kaneko H, Wada H. 2015. Non-destructive method for species identification of historical wooden statues using NIR spectroscopy: analysis using wood samples of the internationally authorized collection. Mokuzai Hozon (Wood Protection) 41: 162-170 (in Japanese).

Abe H, Watanabe K, Ishikawa A, Noshiro S, Fujii T, Iwasa M, Kaneko H, Wada H. 2016. Simple separation of Torreya nucifera and Chamaecyparis obtusa wood using portable visible and near-infrared spectrophotometry: differences in light-conducting properties. J. Wood Sci. 62: 210-212. DOI: 10. 1007/s10o86-016-1541-z.

Adedipe OE, Dawson-Andoh B, Slahor J, Osborn L. 20o8. Classification of red oak (Quercus rubra) and white oak (Quercus alba) wood using a near infrared spectrometer and soft independent modeling of class analogies. J. Near Infrared Spectrosc. 16: 49-57. DOI: 10.1255/jnirs.76o.

Ali M, Emsley AM, Herman H, Heywood RJ. 2001. Spectroscopic studies of the ageing of cellulosic paper. Polymer 42: 2893-29oo. DOI: 10.1016/Soo32-3861(oo)oo691-1.

Bokobza L. 2002. Origin of near-infrared absorption bands. In: Siesler HW, Ozaki Y, Kawata S, Heise HM (eds.), Near-infrared spectroscopy — principles, instruments, applications: $33-35$. Wiley-VCH, Weinheim, Germany. 
Brunner M, Eugster R, Trenka E, Bergamin-Strotz L. 1996. FT-NIR spectroscopy and wood identification. Holzforschung 50: 130-134.

Dunn III WJ, Wold S. 1980. Relationships between chemical structure and biological activity modeled by SIMCA pattern recognition. Bioorg. Chem. 9: 505-523. DOI: 10.1016/0o45-2068(80)90o10-3.

Flæte PO, Haartveit EY, Vadla K. 20o6. Near infrared spectroscopy with multivariate statistical modeling as a tool for differentiation of wood from tree species with similar appearance. New Zealand J. For. Sci. 36: 382-392.

Fujimoto T, Kurata Y, Matsumoto K, Tsuchikawa S. 2010. Feasibility of near-infrared spectroscopy for online multiple trait assessment of sawn lumber. J. Wood Sci. 56: 452-459. DOI: 10.1366/ oo०370210790572016.

Furumoto H, Lampe U, Meixner H, Roth C. 1999. Infrarotanalyse zur messung der holzqualität. Holz als Roh- und Werkstoff 57: 23-28 (in German). DOI: 10.1007/soo1070050004.

Gierlinger N, Schwanninger M, Wimmer R. 2004. Characteristics and classification of Fouriertransform near infrared spectra of the heartwood of different larch species (Larix sp.). J. Near Infrared Spectrosc. 12: 113-119. DOI: 10.1255/jnirs.415.

Hein PRG, Campos ACM, Mendes RF, Mendes LM, Chaix G. 2o11. Estimation of physical and mechanical properties of agro-based particleboards by near infrared spectroscopy. Holz als Roh und Werkstoff 69: 431-442. DOI: 10.1007/s00107-010-0471-5.

Horikawa Y, Mizuno-Tazuru S, Sugiyama J. 2015. Near-infrared spectroscopy as a potential method for identification of anatomically similar Japanese diploxylons. J. Wood Sci. DOI: 10.1007/s10o86015-1462-2.

Kaneko H, Iwasa M, Noshiro S, Fujii T. 1998. Wood types and material selection for Japanese wood statues of ancient period: particularly the 7 th-8th century. Museum 555:3-54 (in Japanese).

Kaneko H, Iwasa M, Noshiro S, Fujii T. 2003. Wood types and material selection for Japanese wood statues of ancient period 2: particularly of the 8th-9th centuries. Museum 583: 5-44 (in Japanese).

Kaneko H, Iwasa M, Noshiro S, Fujii T. 2010. Wood types and material selection for Japanese wood statues of ancient period 3 : further thoughts on 8th and 9 th century sculptures. Museum 625: 61-78 (in Japanese).

Meza-Marquez OG, Gallardo-Velazquez T, Osorio-Revilla G. 2010. Application of mid-infrared spectroscopy with multivariate analysis and soft independent modeling of class analogies (SIMCA) for the detection of adulterants in minced beef. Meat. Sci. 86:511-519. DOI: 10.1016/j.meatsci.2O1O. 05.044 .

Schimleck L, Michell AJ, Vinden P. 1996. Eucalypt wood classification by NIR spectroscopy and principal components analysis. Appita J. 49: 319-324.

Schwanninger M, Carlos J, Fackler K. 2011. A review of band assignments in near infrared spectra of wood and wood components. J. Near Infr. Spectroscopy 19: 287-308. DOI: 10.1255/jnirs.955.

Shenk JS, Workman JJ, Westhaus MO. 20o8. Application of NIR spectroscopy to agricultural products. In: Burns DA, Ciurczak EW (eds.), Handbook of near-infrared analysis, 3rd Edn.: 356-357. Taylor \& Francis Group, New York.

Sjöström E. 1993. Wood chemistry, fundamentals and applications, 2nd Edn. Academic Press, London.

Tominaga Y. 1999. Comparative study of class data analysis with PCA-LDA, SIMCA, PLS, ANNs, and k-NN. Chemom. Intel. Lab. Syst. 49: 105-115.

Tsuchikawa S, Inoue K, Mitsui K. 2004. Spectroscopic monitoring of wood characteristics variation by light-irradiation. For. Prod. J. 54(11): 71-76.

Tsuchikawa S, Inoue K, Noma J, Hayashi K. 2003a. Application of near-infrared spectroscopy to wood discrimination. J. Wood Sci. 49: 29-35. DOI: 10.1007/s10o86o30ooo5.

Tsuchikawa S, Yamato K. 2003. Discriminant analysis of wood-based materials with weathering damage by near infrared spectroscopy. J. Near Infrared Spectrosc. 11: 391-399. DOI: 10.1255/jnirs.39o.

Tsuchikawa S, Yamato K, Inoue K. 2003b. Discriminant analysis of wood-based materials using nearinfrared spectroscopy. J. Wood Sci. 49: 275-28o. DOI: 10.1007/s10o86-oo2-0471-o. 
Watanabe K, Abe H, Kataoka Y, Noshiro S. 2011. Species separation of aging and degraded solid wood using near infrared spectroscopy. Jap. J. Hist. Bot. 19: 117-124.

Williams RS. 2005. Weathering of wood. In: Rowell RM (ed.), Wood chemistry and wood composites: 139-185. Taylor \& Francis Group, New York.

Edited by Lloyd Donaldson 